\title{
Announcement
}

\section{3rd European Pancreatic Club}

Toulouse, France, June 13-16, 2001

Our goal is to gain new insights into a broad range of fields, exploring the potential clinical impact of basic research in relation to pancreatic diseases, diagnosis, therapy and/or prevention. In addition to lectures by invited speakers, selected oral free presentations of original research work and poster sessions are included. A training course will be organized on Wednesday, June 13, supported by the Graduate School of Biology and Health Sciences, MD-PhD Program, University Paul Sabatier, Toulouse, on 'Genomics and post-genomic developments in biomedical sciences'.

For further information:

Nicole Vaysse, MD, PhD

INSERM U531, IFR31

CHU Rangueil

F-31403 Tousouse (France)

Tel. +33561322402

Fax +33561322403

E-Mail nicole.vaysse@rangueil.inserm.fr

www.e-p-c.org 